\title{
L-BSE experimentally transmitted to sheep presents as a unique disease phenotype
}

\author{
Marion M. Simmons ${ }^{1 *}\left(\mathbb{0}\right.$, Melanie J. Chaplin ${ }^{1}$, Timm Konold ${ }^{1,2}$, Cristina Casalone $^{3}$, Katy E. Beck ${ }^{1}$, Leigh Thorne ${ }^{4}$, \\ Sharon Everitt ${ }^{1}$, Tobias Floyd ${ }^{1}$, Derek Clifford ${ }^{1,2}$ and John Spiropoulos ${ }^{1}$
}

\begin{abstract}
Apart from prion protein genotype, the factors determining the host range and susceptiblity for specific transmissible spongiform encephalopathy agents remain unclear. It is known that bovine atypical L-BSE can transmit to a range of species including primates and humanised transgenic mice. It is important, therefore, that there is as broad an understanding as possible of how such isolates might present in food animal species and how robust they are on inter- and intra-species transmission to inform surveillance sytems and risk assessments. This paper demonstrates that L-BSE can be intracerebrally transmitted to sheep of several genotypes, with the exception of ARR/ARR animals. Positive animals mostly present with a cataplectic form of disease characterized by collapsing episodes and reduced muscle tone. PrP accumulation is confined to the nervous system, with the exception of one animal with lymphoreticular involvement. In Western blot there was maintenance of the low molecular mass and glycoform profile associated with L-BSE, irrespective of ovine host genotype, but there was a substantially higher N-terminal antibody signal relative to the core-specific antibody, which is similar to the ratio associated with classical scrapie. The disease phenotype was maintained on experimental subpassage, but with a shortened survival time indicative of an original species barrier and subsequent adaptation. Passive surveillance approaches would be unlikely to identify such cases as TSE suspects, but current statutory active screening methods would be capable of detecting such cases and classifying them as unusual and requiring further investigation if they were to occur in the field.
\end{abstract}

\section{Introduction}

The transmissible spongiform encephalopathies (TSE), fatal neurodegenerative diseases of animals, have been recognised for nearly three hundred years. Despite similar diseases occurring in man (e.g. [1]) the animal TSE were not regarded as zoonotic until the emergence in 1996 of variant Creutzfeldt-Jakob Disease (vCJD), linked to bovine spongiform encephalopathy (BSE) [2-4] which was first described in cattle in the 1980s [5]. The subsequent BSE epidemic, driven by the recycling of the agent in feedstuffs, affected nearly 200000 cattle in the UK and, to a lesser extent, elsewhere, particularly in Europe [6]. It

\footnotetext{
*Correspondence: marion.simmons@apha.gsi.gov.uk

1 Department of Pathology, APHA Weybridge, Woodham Lane

Addlestone, Surrey KT15 3NB, UK

Full list of author information is available at the end of the article
}

is thought to have been attributable to a single strain of agent [7-9], now referred to as classical BSE (C-BSE).

Following the implication of BSE as the origin of vCJD in man, substantial effort and expense has gone into ensuring the safety of the animal feed and human food chains. It was established through experimental challenge that sheep and goats were susceptible to C-BSE $[10,11]$ and a formal component of disease surveillance currently requires the classification of all TSE positive small ruminant isolates as "BSE-like" or "non-BSE-like" [EC TSE surveillance regulations (999/2001 as amended 36/2005)]. This reflects the hypothetical risk that would have been posed to the sheep population through exposure to BSEcontaminated concentrate feeds prior to the banning of mammalian protein in mammalian feedstuffs. These concerns have since been reinforced by the identification of 
two naturally-occurring cases of classical BSE in goats, one in France [12] and one in Scotland [13, 14].

Since its introduction in 2001, systematic EU-wide active surveillance for TSE in cattle and small ruminants [EU reg 999/2001] has resulted in the detection of two additional forms of BSE in cattle, commonly referred to collectively as "atypical", that affected mainly cattle eight years of age or older (for reviews see $[15,16]$ ). These cases were characterised as different from C-BSE, and designated H-BSE and L-BSE (also referred to as bovine amyloidotic spongiform encephalopathy (BASE) [17]), based on molecular features of the disease-associated form $\left(\operatorname{PrP}^{\mathrm{Sc}}\right)$ of the host $\operatorname{PrP}$, or prion protein, which is the marker recognised by all current surveillance tests $[18,19]$. To date, none of the "atypical" BSE cases diagnosed in various countries in cattle (Bos taurus) have been reported as clinical TSE suspects, and most cases have been identified through the surveillance of fallen stock. Given the rarity of these cases, and their widespread geographical distribution it has been speculated, but not yet established, that these atypical forms of disease are genetic in origin and/or arise spontaneously, and that they may be the origin of classical BSE [20,21]. Even if there is no evidence of natural spread between animals in the field, these variants have been shown (like C-BSE) to transmit experimentally into a range of host species.

There is still no robust understanding of what makes a particular host susceptible, or a TSE isolate zoonotic [22], and it has been demonstrated that atypical BSE can transmit to a range of species including primates [23-25] and humanised transgenic mice [26, 27]. It is important, therefore, that there is as broad an understanding and awareness of how such isolates present in food animal species, how robust they are on inter- and intra-species transmission, and that they are characterised as fully as possible to assist with the maintenance of robust surveillance sytems and the assessment of risk to both human and animal health.

The susceptibility of sheep to scrapie and BSE is strongly influenced by different polymorphisms of the PRNP gene that encodes for prion protein (PrP), with polymorphisms at codons 136 (A or V), 141 (L or F), $154(\mathrm{R}$ or $\mathrm{H})$ and $171(\mathrm{R}, \mathrm{Q}$ or $\mathrm{H})$ demonstrated to be of major importance (for recent review, see [16]). Therefore, when investigating the transmissibility to sheep of any non-ovine isolates, it is important to consider a range of host genotypes, to account for potentially variable susceptibility.

This paper presents a study of the transmissibility and characterisation of L-BSE in sheep of various genotypes, and assesses whether the current surveillance requirements would be sufficient to detect and classify such cases if they were to occur in the field.

\section{Materials and methods}

\section{Animal experimentation}

All inoculations were carried out under general anaesthesia and in accordance with the United Kingdom (UK) Animal (Scientific Procedures) Act 1986, under license from the UK Government Home Office (Project licence no: 70/6781). Such license is only granted following approval by the internal Animal and Plant Health Agency (APHA) ethical review process as mandated by the Home Office.

Inoculum $(10 \% \mathrm{w} / \mathrm{v}$ brain homogenate in normal saline) was prepared from an Italian L-BSE field case (141387/02), and stored at $-80^{\circ} \mathrm{C}$ prior to use. TSE negative bovine brain, previously sourced from New Zealand, was used as a negative control inoculum with the kind agreement of the New Zealand authorities.

All recipient sheep were supplied from the Defra New Zealand-derived flock [28] and were 4-6 months old at inoculation. For the primary passage, five sheep of each of five PRNP genotypes $\mathrm{A}_{136} \mathrm{~F}_{141} \mathrm{R}_{154} \mathrm{Q}_{171}$ /AFRQ, ARR/ ARR, ARQ/ARQ; ARQ/VRQ, VRQ/VRQ [the amino acid at codon 141 ( $\mathrm{L}$ in wild-type, $\mathrm{F}$ when polymorphic) is only indicated when it deviates from the wild type] were inoculated intracerebrally (IC) with $1 \mathrm{~mL}$ of inoculum. All sheep were housed for the duration of the study in biosecure accommodation that had never previously housed any TSE affected animals, and was fully cleaned and disinfected (20\% Chloros) prior to use. Each pen had separate equipment and personal protective clothing. Animals were handled and observed daily as part of routine husbandry procedures, until clinical disease developed, or until a pre-determined experimental endpoint of approximately 5 years post-inoculation (pi). A further two sheep of each genotype were inoculated with negative control brain material and housed in the same building but separated by a concrete wall so that they only shared the same air space.

Following the identification of the first positive animals in the primary passage study, inoculum for sub-passage was prepared from two positive sheep, one AFRQ/ AFRQ and one ARQ/VRQ. These animals were selected to reflect the two slightly different clinical presentations that had been observed in the animals that had succumbed to disease at that time. Each ovine source was used to inoculate five AFRQ/AFRQ and five ARQ/VRQ recipients. Both inoculation groups were housed in separate pens, similar to the primary passage study.

\section{Clinical monitoring}

All sheep were examined neurologically prior to inoculation, then monitored daily during routine husbandry procedures (feeding, bedding changes) and weighed monthly. Weight loss prior to cull was expressed in 
percent of the previous body weight determined prior to weight loss. Routine clinical examinations [29] were conducted quarterly from 8 months pi (primary passage) and 6 months pi (sub-passage), increasing to weekly for any formal suspect animal. Additional neurological examinations [30] were conducted prior to cull (with the exception of the first culled sheep, which was last examined 2 months prior to death), or if animal husbandry staff noted any signs suggestive of a neurological disease. Inoculated animals were also monitored during the daytime by CCTV.

The clinician was unaware of the genotype of specific challenged animals but the identity of the control group in the primary passage was known because these animals were always examined first.

Clinical end-point was considered to have been reached when sheep displayed progressive abnormalities in sensation (positive scratch test with or without alopecia, absent menace response) and movement (ataxia, limb weakness, tremor). In addition, the display of signs likely to result in permanent recumbency or death, such as seizures or collapse not triggered by human intervention, was considered to be a clinical end-point, which resulted in cull using quinalbarbitone sodium (Somulose, Arnolds) intravenously. Animals, including the controls, that remained healthy throughout the study, were killed at the end of the study. One control animal from each genotype pair was killed after the last animal in the matched genotype challenged group succumbed, and the others were kept until the endpoint of the study, approximately 5 years post challenge.

\section{Pathology and immunohistochemistry}

Postmortem, the whole brain was removed from each sheep and hemisected longitudinally. One half of the brain was placed into $10 \%$ formal saline for histology, and the other half stored at $-80^{\circ} \mathrm{C}$. Samples representative of the trigeminal, nodose, cranial cervical, stellate and coeliaco-mesenteric ganglia, the lateral retropharyngeal and mesenteric lymph nodes, the recto-anal mucosa-associated lymphoid tissue (RAMALT), the spleen, the distal ileum (with Peyer's patches) and the extraocular muscles were also collected into $10 \%$ buffered formalin.

All brain tissue was routinely fixed, blocked to represent the major levels of the neuraxis and processed, sectioned and stained with haematoxylin and eosin as described in detail elsewhere [31]. Immunohistochemical detection of $\mathrm{PrP}^{\mathrm{Sc}}$ was performed on adjacent sections from the same brain blocks, and on the other tissues, using mouse monoclonal antibody (mAb) 2G11 (ABD Serotec), raised against the ovine $\operatorname{PrP}$ peptide sequence $146-R_{154} R_{171}-182$, as described in detail elsewhere [32]. Sections from the obex were also immunolabelled with the $\mathrm{mAb}$ P4, which can be used to discriminate ovine BSE from scrapie [33]. Vacuolation and immunohistochemistry profiles were created using standard subjective methods as previously described [31,34] in which the severity of vacuolar lesions, or the type of PrP immunolabelling, is assessed in a standard range of precise neuroanatomical areas. Some modifications were made to the original method [34] to accommodate the range of morphological $\mathrm{PrP}^{\mathrm{Sc}}$ immunolabelling types first identified in atypical scrapie.

\section{Western immunoblot}

All samples were subjected to the BioRad TeSeE ${ }^{\mathrm{TM}}$ Western immunoblot (according to the manufacturer's instructions) and, run on two replicate gels (18.75 $\mathrm{mg}$ tissue equivalent per well). The primary antibodies were Sha31 (prepared according to the kit protocol) and P4 $(0.2 \mu \mathrm{g} /$ $\mathrm{mL}, \mathrm{RIDA}^{\circledR}, \mathrm{r}$-Biopharm). The signal was developed using ECL detection blotting reagents, detected and analysed with exposure times of 1 and 10 min using Biorad Quantity One vers. 4.6.9 software on Fluor-S Max imager. Where Sha31 and P4 antibody ratio calculations were performed the images for both antibodies were obtained at the same time and $1 \mathrm{~min}$ exposure times were used.

The original bovine donor animal, a classical bovine BSE field case, an ovine classical scrapie field case, an experimentally transmitted ovine BSE [35] and a negative ovine sample were used as controls alongside the primary passaged samples. The same field case bovine BSE and ovine scrapie controls were used as controls alongside the sub-passaged samples.

Western immunoblots were also performed on retropharyngeal lymph node from the single primary passage pre-clinical VRQ/VRQ animal which displayed peripheral tissue involvement. Brain tissue from the same animal, lymphoid and brain tissue from experimentally transmitted ovine classical BSE and brain tissue from the field case bovine BSE and field case ovine BSE were used as comparative controls.

\section{Elisa}

Samples from all positive animals from the primary passage were subject to four commercially available ELISA tests-IDEXX Herdchek ${ }^{\text {TM }}$ with bovine conjugate, IDEXX Herdchek $^{\mathrm{TM}}$ with ovine conjugate, BioRad $\mathrm{TeSeE}^{\mathrm{TM}}$ and BioRad $S \& G^{\mathrm{TM}}$. For each test, samples were extracted and the tests carried out in accordance with the manufacturers' instructions.

\section{Results}

Details of all inoculated animals can be found in Table 1 . There was a wide range of overlapping incubation periods for each affected genotype in the primary passage. 
Table 1 Summary of inoculation outcomes with survival times and rates

\begin{tabular}{|c|c|c|c|c|c|}
\hline Passage & $\begin{array}{l}\text { Recipient } \\
\text { genotype }\end{array}$ & $\begin{array}{l}\text { No positive/ } \\
\text { challenged }\end{array}$ & $\begin{array}{l}\text { Individual survival } \\
\text { times (dpi) for positive } \\
\text { sheep }\end{array}$ & $\begin{array}{l}\text { Mean ip }( \pm S D) \text { of clinically } \\
\text { positive sheep }\end{array}$ & $\begin{array}{l}\text { Mean survival } \\
\text { times }(+\mathrm{SD}) \\
\text { of negative sheep }\end{array}$ \\
\hline \multirow[t]{5}{*}{ Primary } & VRQ/VRQ & $4 / 5$ & $1183,1337,1439,1963^{\mathrm{a}}$ & $1320 \pm 129$ & 1964 \\
\hline & VRQ/ARQ & $5 / 5$ & $803^{b}, 864,957,1056,1389$ & $1014 \pm 231$ & \\
\hline & $\mathrm{ARQ} / \mathrm{ARQ}$ & $5 / 5$ & $956,959,1186,1531,1649$ & $1256 \pm 321$ & \\
\hline & AFRQ/AFRQ & $4 / 5$ & $1186^{b}, 1236,1267,1334$ & $1256 \pm 62$ & $867^{c}$ \\
\hline & ARR/ARR & $0 / 5$ & & & $2001 \pm 3$ \\
\hline \multirow{2}{*}{$\begin{array}{l}\text { Subpassage: Donor } \\
\text { ARQ/NRQ }\end{array}$} & ARQ/NRQ & $5 / 5$ & $433,454,462,478,478$ & $461 \pm 19$ & \\
\hline & AFRQ/AFRQ & $5 / 5$ & $503,505,527,552,552$ & $528 \pm 24$ & \\
\hline \multirow{2}{*}{$\begin{array}{l}\text { Subpassage:Donor } \\
\text { AFRQ/AFRQ }\end{array}$} & ARQ/NRQ & $5 / 5$ & $461,488,496,501,531$ & $495 \pm 25$ & \\
\hline & AFRQ/AFRQ & $5 / 5$ & $473,519,520,520,539$ & $514 \pm 25$ & \\
\hline
\end{tabular}

a Preclinical animal, detected at end of study cull (not included in mean survival time calculation).

b Animals used as donors for the sub-passage study.

c Intercurrent disease loss.

The survival periods for the sheep in the sub-passage study were substantially shorter than those of the donor animals.

Using the two-sample Kolmogorov-Smirnov tests of the equality of distributions, pairwise comparison of the sub-passage groups revealed that the survival period in the ARQ/VRQ homologous transmission group was significantly different to those of the other three groups (ARQ/VRQ donor to AFRQ/AFRQ recipient: $p=0.007$; AFRQ/AFRQ donor to AFRQ/AFRQ recipient: $p=0.05$; AFRQ/AFRQ donor to ARQ/VRQ recipient: $p=0.05$.) The ARQ/VRQ donor into AFRQ/AFRQ recipient group, and the AFRQ/AFRQ donor into the ARQ/VRQ recipient group were also significantly different from each other $(p=0.05)$.

\section{Clinical observations}

The 10 control animals inoculated with normal brain survived to the relevant endpoint of the study; three (one AFRQ/AFRQ, one ARQ/ARQ and one ARQ/VRQ) were killed after the last challenged animal in the relevant challenge group succumbed to clinical disease, at $1678 \pm 20$ days post challenge (dpi). Neurological signs indicative of a vestibular disease were seen in one sheep (39/13, AFRQ/AFRQ) from 1376 dpi. A positive scratch test [29] was displayed irregularly by seven sheep between 915 and $1681 \mathrm{dpi}$ attributable to hay in the fleece and/or lesions suggestive of Chorioptes mange. Neither wool loss nor weight loss was recorded in any of the control animals prior to cull. The remaining seven control animals were culled at $1978 \pm 1 \mathrm{dpi}$.

From the primary passages, only two VRQ/VRQ animals and the five ARR/ARR animals survived to the pre-determined cull point at approximately 5 years post challenge. None of the ARR/ARR sheep displayed signs suggestive of a neurological disease, but both VRQ/ VRQ sheep inconsistently displayed fore limb hypermetria and circled when blindfolded, from 1225 and 1713 dpi respectively. Both sheep were considered clinically healthy at cull. At post-mortem, one of the VRQ/VRQ animals (48/13) was found to be positive by all diagnostic methods, while the other clinically normal animals were negative by all tests.

One AFRQ/AFRQ sheep developed changes in behavior and mental status (confusion, separation from others, pica) from $860 \mathrm{dpi}$ and subsequent ataxia, hypermetria, circling and loss of balance when blindfolded, but no weight loss. This sheep was culled at $867 \mathrm{dpi}$ as a TSE suspect, but TSE was not confirmed by postmortem testing.

In the primary passage study, two clinical syndromes were described based on the major presenting clinical sign (Table 2). Pruritic behaviour (rubbing, scratching and nibbling itself) resulting in wool loss and later ataxia, which was indistinguishable from the pruritic form of classical scrapie, or experimental ovine classical BSE [35] was displayed by two sheep. These sheep also presented with a positive scratch test that could later be elicited by merely applying firm pressure on the back (see Additional file 1: pruritic form). More frequently, affected animals presented with a cataplectic form of disease, characterized by collapsing episodes with reduced muscle tone, often with low head carriage and initially triggered by lifting of the head or more stressful events (e.g. foot trimming, restraint for clinical examinations), although in the later stages this occurred during feeding time or in the absence of any obvious stimulus. Initially 
Table 2 Clinical syndromes in sheep challenged with L-type BSE

\begin{tabular}{|c|c|c|c|c|}
\hline Passage & Animal ID & Genotype & Syndrome & Other neurological and behavioural signs \\
\hline \multirow[t]{17}{*}{ Primary } & $456 / 11$ & VRQNRQ & Cataplectic $^{\mathrm{a}}$ & None \\
\hline & $113 / 12$ & & Cataplectic & Ataxia \\
\hline & $167 / 12$ & & Cataplectic & $\begin{array}{l}\text { Head tremor, occasionally horizontal nystagmus during } \\
\text { collapsing episodes, teeth grinding }\end{array}$ \\
\hline & $1591 / 10^{b}$ & VRQ/ARQ & Undefined, (possibly pruritic) & Seizure-like episode, positive scratch test \\
\hline & $58 / 11$ & & Cataplectic & Dullness, ataxia, loss of balance \\
\hline & $4 / 12$ & & Cataplectic & Head tremor, ataxia \\
\hline & $140 / 11$ & & Cataplectic & Positive scratch test, head tremor, ataxia \\
\hline & $267 / 11$ & & Cataplectic & Positive scratch test, ataxia \\
\hline & $63 / 11$ & $\mathrm{ARQ} / \mathrm{ARQ}$ & Pruritic & Dullness, head tremor, ataxia, loss of balance \\
\hline & $3 / 11$ & & Cataplectic & Positive scratch test, ataxia, loss of balance \\
\hline & $182 / 12$ & & Pruritic & Positive scratch test, ataxia, loss of balance \\
\hline & $3 / 13$ & & Cataplectic & $\begin{array}{l}\text { Dullness, teeth grinding, absent menace response, ataxia, } \\
\text { loss of balance }\end{array}$ \\
\hline & $455 / 11$ & & Cataplectic & Positive scratch test, ataxia \\
\hline & $98 / 11^{b}$ & AFRQ/AFRQ & Cataplectic & Ataxia \\
\hline & $457 / 11$ & & Cataplectic & Head tremor, ataxia \\
\hline & $26 / 12$ & & Cataplectic & Head tremor, ataxia, loss of balance \\
\hline & $112 / 12$ & & Cataplectic & Positive scratch test, head tremor, ataxia \\
\hline \multirow[t]{10}{*}{ Subpassage: donor VRQ/RQ } & $112 / 14$ & $\mathrm{ARQ} / \mathrm{ARQ}$ & Cataplectic & $\begin{array}{l}\text { Dullness, positive scratch test, absent menace response, } \\
\text { head tremor, ataxia, loss of balance, circling }\end{array}$ \\
\hline & $120 / 14$ & & Cataplectic & $\begin{array}{l}\text { Positive scratch test, absent menace response, head } \\
\text { tremor, ataxia, circling, teeth grinding }\end{array}$ \\
\hline & $119 / 14$ & & Cataplectic & $\begin{array}{l}\text { Positive scratch test, head tremor, ataxia, loss of balance, } \\
\text { circling }\end{array}$ \\
\hline & $107 / 14$ & & Cataplectic & $\begin{array}{l}\text { Absent menace response, head tremor, ataxia, teeth } \\
\text { grinding }\end{array}$ \\
\hline & $108 / 14$ & & Cataplectic & Head tremor, ataxia, circling \\
\hline & $79 / 14$ & $\mathrm{ARQ} / \mathrm{RQ}$ & Cataplectic & Positive scratch test, head tremor, loss of balance \\
\hline & $78 / 14$ & & Cataplectic & Positive scratch test \\
\hline & $76 / 14$ & & Cataplectic & Head tremor \\
\hline & $6 / 14$ & & Cataplectic & Ataxia \\
\hline & $73 / 14$ & & Cataplectic & Absent menace response, head tremor, loss of balance \\
\hline \multirow[t]{9}{*}{ Subpassage: donor AFRQ/AFRQ } & $109 / 14$ & $\mathrm{ARQ} / \mathrm{ARQ}$ & Cataplectic & Absent menace response, head tremor \\
\hline & $110 / 14$ & & Cataplectic & Absent menace response, head tremor, ataxia \\
\hline & $111 / 14$ & & Cataplectic & Absent menace response, head tremor, ataxia \\
\hline & $118 / 14$ & & Cataplectic & Absent menace response, head tremor, ataxia \\
\hline & $77 / 14$ & & Cataplectic & Absent menace response, ataxia \\
\hline & $81 / 14$ & $\mathrm{ARQ} / \mathrm{RQ}$ & Cataplectic & Head tremor, loss of balance \\
\hline & $80 / 14$ & & Cataplectic & Head tremor, teeth grinding \\
\hline & $117 / 14$ & & Cataplectic & Head tremor, ataxia, loss of balance \\
\hline & $82 / 14$ & & Cataplectic & Head tremor, ataxia, loss of balance, circling \\
\hline
\end{tabular}

a Cataplexy is spontaneous collapse due to complete atonia of skeletal muscles, often associated with narcolepsy (disorder of normal sleep mechanism, usually excessive sleep). The latter may also be a feature in affected L-type BSE-inoculated sheep but is difficult to diagnose.

b Animals selected for subpassage.

these episodes were usually very brief, with loss of muscle tone in the limbs causing sheep to drop suddenly to the ground but get up again immediately. With disease progression, complete loss of muscle tone led to lateral recumbency and a complete lack of response, suggestive of narcolepsy (see Additional file 2: cataplectic form). Pruritus was not evident in these cases although some displayed a positive scratch test the significance of which was difficult to interpret given the similar observations in the control sheep. 
The clinical classification was equivocal in the first sheep culled with confirmed TSE (1591/10) because it displayed a positive scratch test without any other signs of pruritus at a time when none of the controls showed this sign but was culled after being observed dropping to the floor with limb muscle contraction, similar to a seizure and contrary to the atonia seen in the cataplectic form (see Additional file 3: seizure-like disorder).

Weight loss of $2.1-14.6 \%$ (mean $6.8 \%$ ) prior to cull was recorded in 15 primary passage sheep $(88 \%)$.

In the subpassage study, one ARQ/VRQ sheep inoculated with the AFRQ/AFRQ donor inoculum was found dead at 461 dpi without any premonitory signs being observed. Minor weight loss (1.7\%) was present prior to death. This sheep was confirmed positive by postmortem examination.

All the other subpassage animals, regardless of the donor/recipient combination, presented with the cataplectic syndrome. Five sheep of one inoculation group also displayed a positive scratch test, probably attributable to the chorioptic mange that was diagnosed in this group.

Nine of the 19 subpassage recipients (47\%) that succumbed to clinical disease lost weight prior to cull (0.8-20.4\%, mean $7.0 \%)$. All 19 sheep were positive by all diagnostic methods.

\section{Pathology}

Vacuolar pathology consistent with TSE was present in all positive cases, with a distribution in the brain that was similar in all L-BSE recipient genotypes (Figure 1) regardless of the clinical presentation or passage history, and distinctly different from animals of the same genotypes infected with classical scrapie or C-BSE [31]. There was limited vacuolation in the brainstem, and the intensity of vacuolation increased markedly in more rostral areas, with high scores for the thalamic areas, the basal ganglia and the cerebral cortex (frontal lobes).

Widespread immunolabelling was present at all levels of the brain and spinal cord with antibody 2G11. In every case, the predominant labelling type was fine particulate in the neuropil (Figure 2), with intraneuronal and glial labelling also present, and some linear forms and small aggregates. Stellate forms were rarely seen. All of the intraneuronal labelling, and most of the neuropil labelling was lost with antibody $\mathrm{P} 4$ (Figures $2 \mathrm{~A}$ and B), which would be diagnostically consistent with a discriminatory interpretation of "BSE-like" [33]. Distinctive perineuronal labelling was seen in the basal ganglia (Figure 2D). Intracellular labelling was also present in the oligodendrocytes.

Detailed mapping using 2 G11 revealed no obvious difference in immunolabelling patterns between animals of different genotypes or clinical presentation groupings. Figure 3 shows the mapping of labelling type distribution in one case (455/11) as representative of the central nervous system pathology seen in all the positive sheep in this study. The one VRQ/VRQ sheep that was identified as pre-clinically affected at the 5 -year cull point (48/13) demonstrated positive immunolabelling throughout the brainstem, but was negative in the cerebellum and cortical regions. The immunolabelling patterns identified in this case were similar to those seen in the other positive animals, but with the addition of stellate forms in several neuroanatomical nuclei.

A range of peripheral tissues from each case was systematically screened by IHC (Table 3). In seventeen of the eighteen positive animals, no immunoreactivity was detected in liver, spleen, lymph nodes, distal ileum or RAMALT. Labelling was consistently seen in the neuronal cell bodies of the trigeminal and nodose ganglia, but not in the cranial cervical or stellate ganglia, or the coeliaco-mesenteric plexi. Labelling of the muscle spindles was seen consistently, and in some cases, occasional labelled myocytes were also observed.

In the one pre-clinical VRQ/VRQ animal, there was positive labelling present in all the lymphoid tissues examined, together with the enteric nervous system and the coeliaco-mesenteric ganglion in addition to the muscle spindles (Figures 2I and J). Unlike the other cases, labelling with P4 was retained in the brainstem, which would be diagnostically consistent with a discriminatory interpretation of "scrapie-like". However, P4 labelling was lost in the lymphoid tissue, which would be consistent with a BSE-like interpretation.

The vacuolar profiles (Figure 1B) and immunohistochemical PrP distribution patterns in the sub-passage animals (not illustrated) were the same as those of the donor animals.

No histological lesions or PrP accumulation were detected in any of the control sheep.

\section{Biochemistry}

All the clinical cases from the primary passage tested positive using all four different ELISA formats (Table 4).

The L-BSE recipients that succumbed to clinical disease were subjected to comparative Western immunoblotting (Figures 4A-D). The samples were grouped according to genotype-those which were ARQ/ARQ, with either F or $\mathrm{L}$ at codon 141 (Figures $4 \mathrm{~A}$ and $\mathrm{B}$ ) and those which carried one or two VRQ alleles (ARQ/VRQ or VRQ/VRQ) (Figures 4C and D).

The donor profile exhibited the three visual characteristics that are associated with L-BSE: a low molecular mass migration, a glycoform ratio where the di- and mono-glycosylated bands contain a more equal proportion of $\mathrm{PrP}^{\mathrm{Sc}}$ than classical BSE when detected with the 

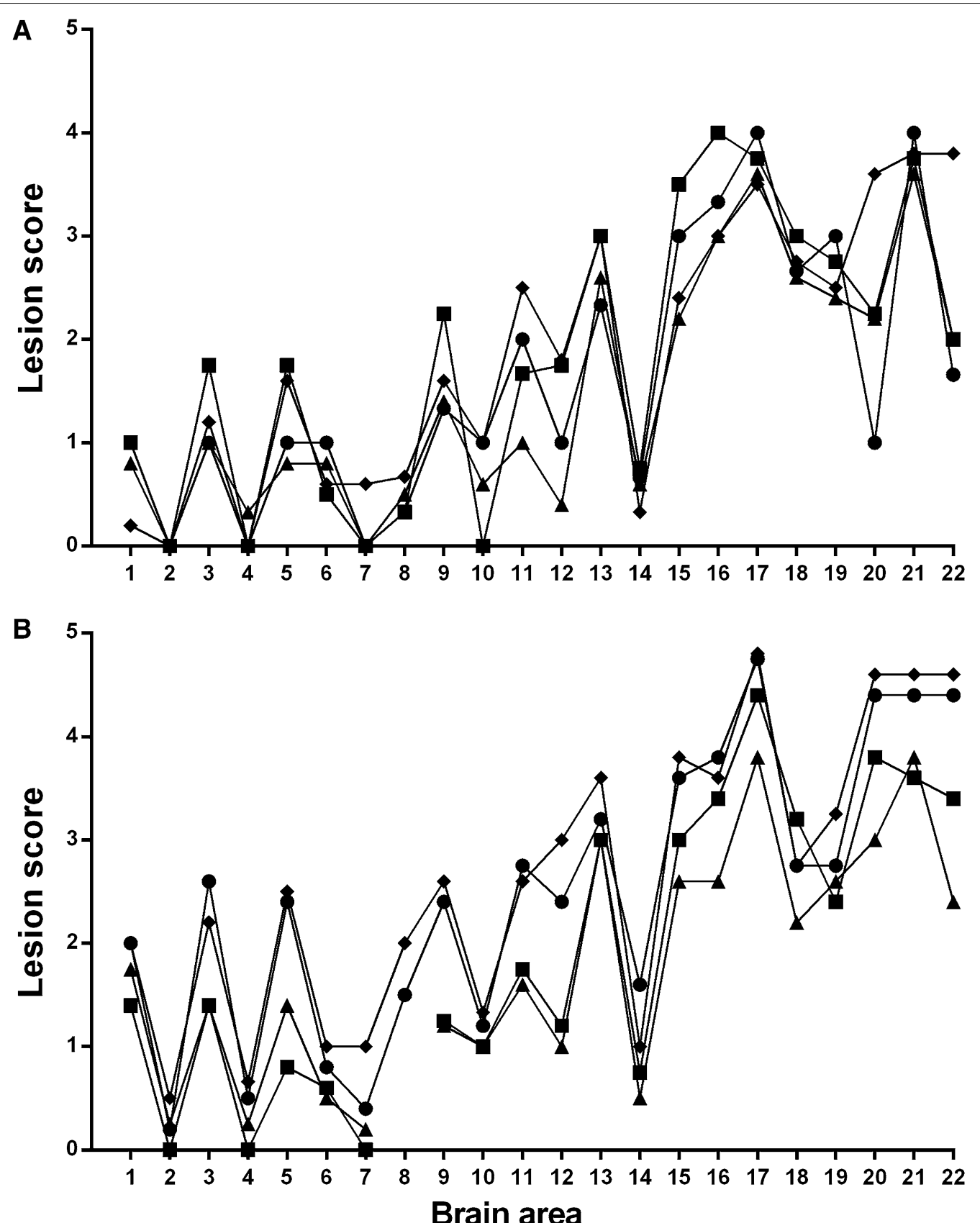

Figure 1 Vacuolar lesion profiles. A Primary transmission of bovine L-BSE to sheep. Square $=A F R Q / A F R Q$ recipients $(n=4)$, diamond $=A R Q$ / $\mathrm{ARQ}$ recipients $(n=5)$, triangle $=\mathrm{ARQ} / \mathrm{NRQ}$ recipients $(n=5)$, circle $=\mathrm{VRQ} / \mathrm{VRQ}$ recipients $(n=3)$. B Subpassages of ovine L-BSE to sheep. Square $=A R Q / N R Q$ recipient, $A R Q / V R Q$ donor $(n=5)$, diamond $=A F R Q / A F R Q$ recipient, $A F R Q / A F R Q$ donor $(n=5)$, triangle $=A R Q / N R Q$ recipient, AFRQ/AFRQ donor $(n=5)$, circle = AFRQ/AFRQ recipient, ARQ/NRQ donor $(n=5)$. X-axis: brain areas from Ligios et al. [31]. 1-11 brainstem areas, 12, 13 the cerebellum, 15-19 midbrain and thalamus, 20-22 the basal ganglia and frontal cortex. Y-axis: mean vacuolation score. Vacuolation is consistently greater in the more rostral brain areas than in the brainstem, regardless of genotype or passage history, with a slight but consistent increase in the intensity of vacuolation throughout the brain following sub-passage.

core $\mathrm{mAb}$ (Sha31), and a lack of detection with the $\mathrm{N}$-terminal $\mathrm{mAb}(\mathrm{P} 4)$.

In affected animals the overall trend observed was maintenance of the low molecular mass and a glycoform profile similar to L-BSE or classical scrapie, irrespective of genotype (representative cases are illustrated in Figure 4 and Additional file 4), although in one VRQ/VRQ sheep (167/12; Lane 8, Figures 4C and D) the molecular 

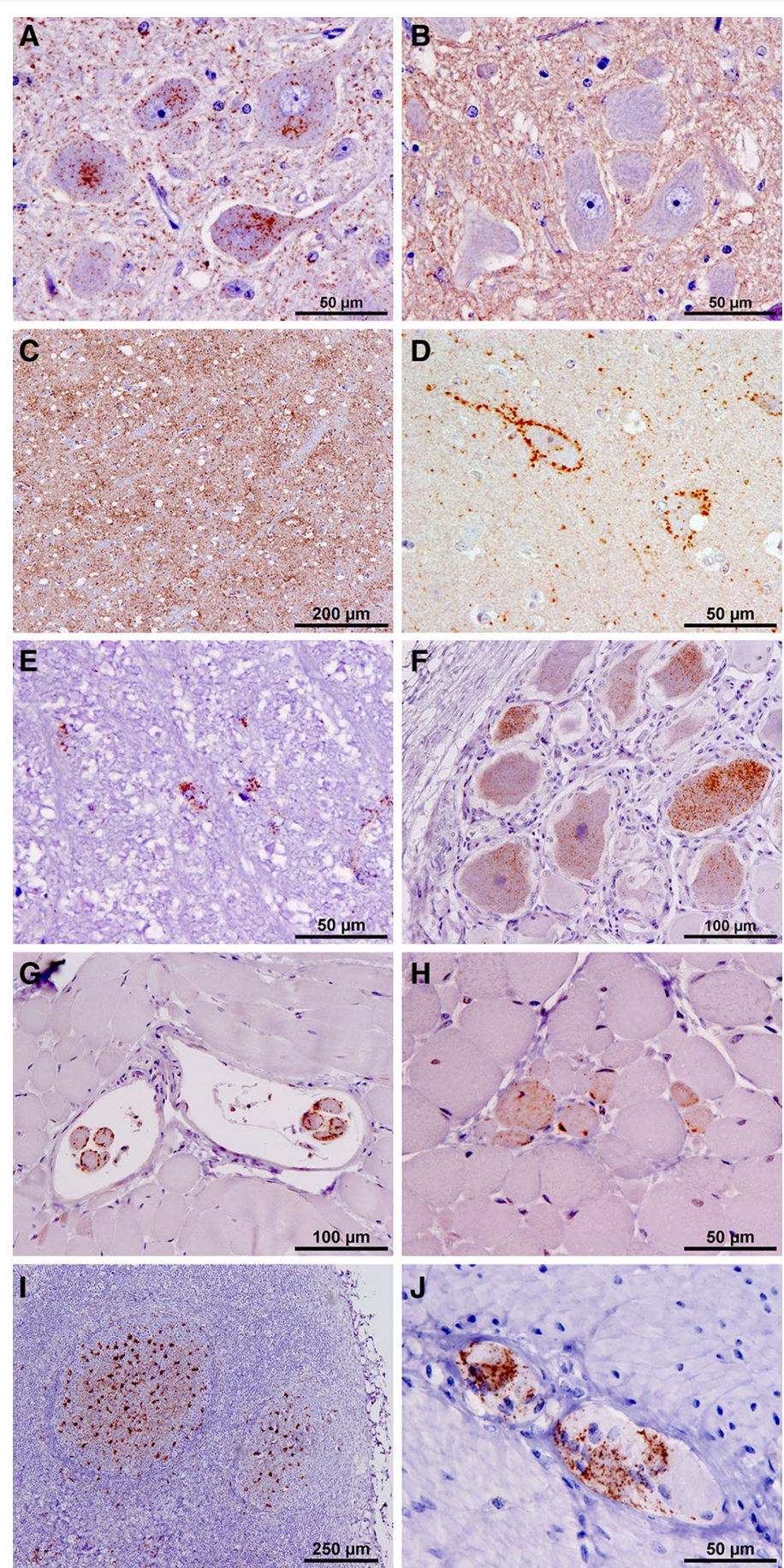

Figure 2 Immunohistochemistry representative of ovine L-BSE. All figures illustrate labelling with mAb 2G11, except B. Neuronal and particulate labelling is present in the DNV with mAb 2G11 (A), but absent with mAb P4 (B) (case 455/11). Particulate labelling and small aggregates are abundant in many areas, such as the thalamic nuclei (C) (case 1591/10). Perineuronal labelling in the putamen is a consistent and striking feature of ovine L-BSE (D) (case 1591/10), as is intracellular labelling of oligodendrocytes, seen here in the spinocerebellar tract (rostral medulla) (E) (case 58/11). Intraneuronal labelling is also present in the DRG (F) (case 4/12). Heavy labelling in muscle spindles is also visible (G) (case 267/11) and also in occasional myocytes (H) (case 98/11). Labelling was also present in the LRS (I) and ENS (J) of one VRQ/VRQ recipient (case 48/13). 

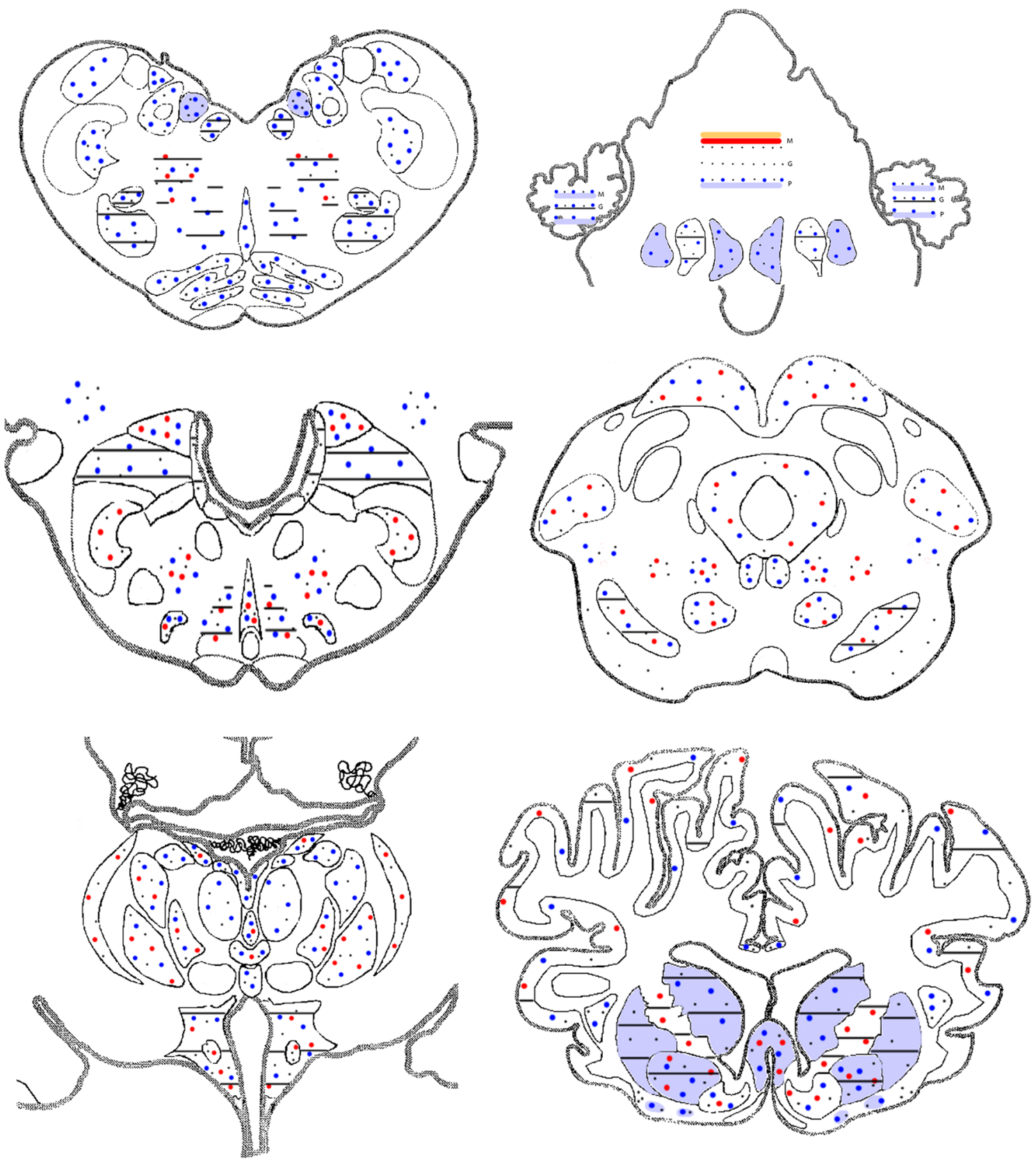

Pattern Key

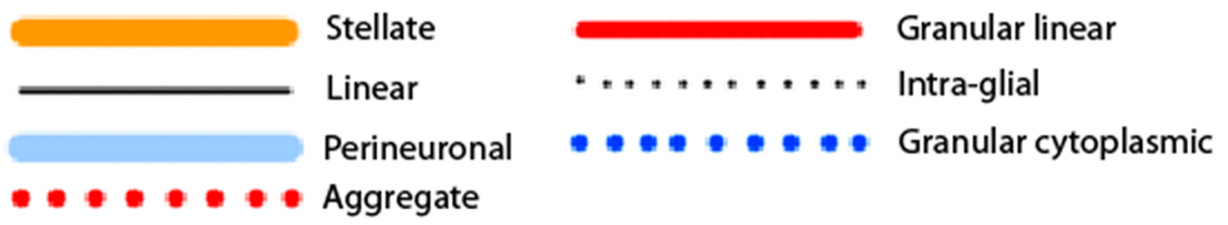

Figure 3 Schematic non-quantitative representation of the neuroanatomical distribution of PrP immunolabelling. Every area that was positive contained particulate labelling, so this has been omitted from the figure to make the presence and distribution of the other labelling types easier to see. This map is based on a single case (case 455/11) as representative of all positive animals. 


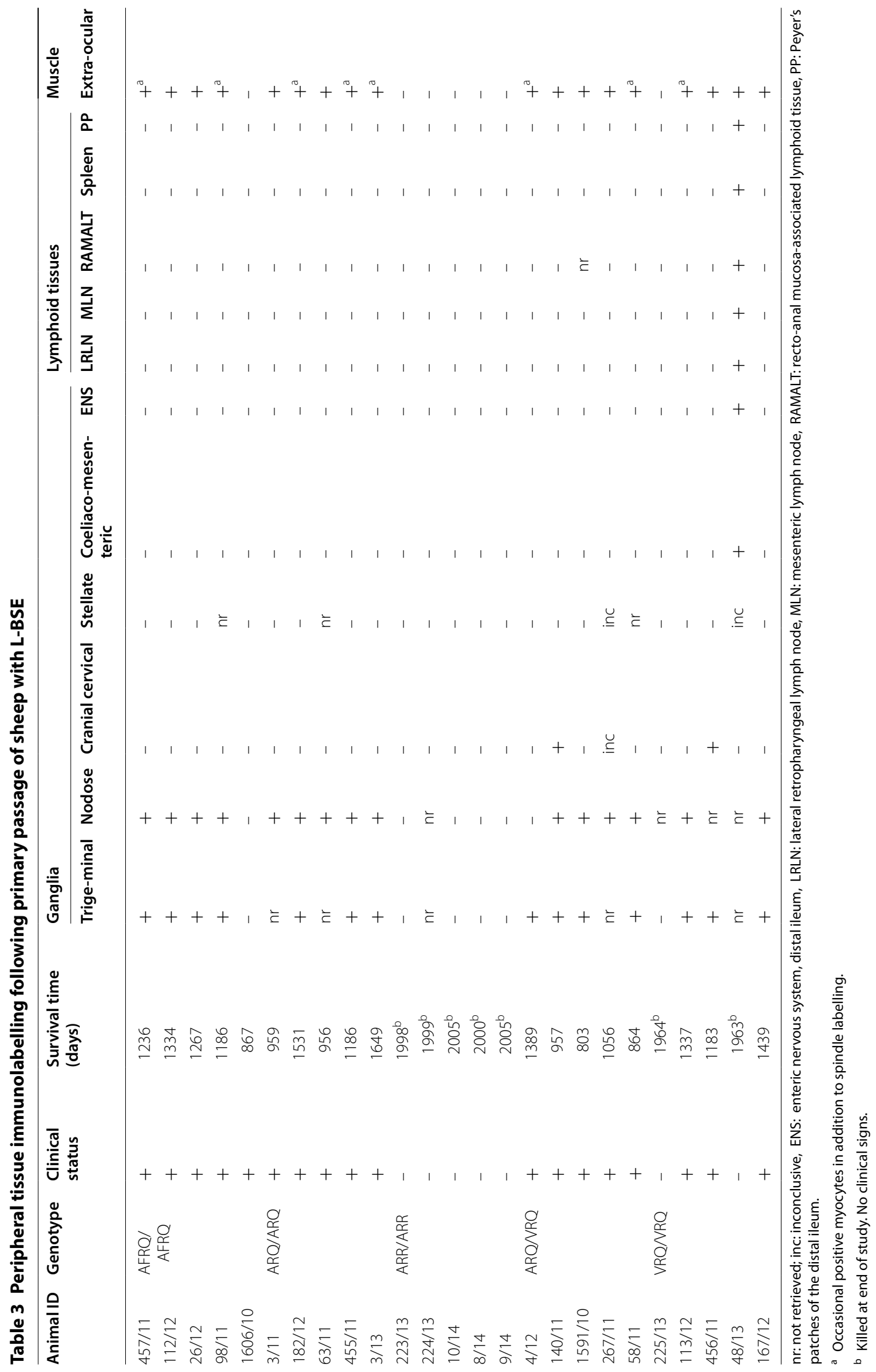


Table 4 Comparative ELISA results for primary challenge animals

\begin{tabular}{|c|c|c|c|c|}
\hline & \multicolumn{4}{|l|}{$\mathrm{OD}( \pm \mathrm{SD})$} \\
\hline & \multicolumn{2}{|c|}{ IDEXX Herdchek BSE/Sc EIA } & \multicolumn{2}{|l|}{ BioRad } \\
\hline & SRB-CCa & $C^{\mathbf{b}}$ & $S \& G^{c}$ & TeSeE \\
\hline Ovine L-BSE primary challenge (all genotypes) $\left(N=17^{d}\right)$ & $2.61( \pm 0.024)$ & $2.62( \pm 0.031)$ & $2.68( \pm 0.057)$ & $2.67( \pm 0.062)$ \\
\hline Ovine C-BSE & 2.636 & 2.668 & 2.631 & 2.661 \\
\hline Ovine scrapie & 2.632 & 2.672 & 2.599 & 2.635 \\
\hline Ovine negative & 0.022 & 0.026 & 0.029 & 0.036 \\
\hline Bovine L-BSE & 2.630 & 2.668 & 0.063 & 2.617 \\
\hline
\end{tabular}

a Small ruminant brain conjugate concentrate.

b Bovine brain conjugate concentrate.

c Sheep and goat.

d Clinical cases only. The pre-clinical VRQ/VRQ is not included.

mass migration of the unglycosylated band was slightly higher than for the other cases. There was a substantial increase in the detection by the $\mathrm{N}$-terminal antibody relative to the bovine L-BSE donor, thereby giving an antibody detection ratio for the recipient animals closer to that obtained with classical scrapie. This was more consistent in ARQ/ARQ animals (Figure 4B; Additional file 4) than in those with valine at codon 136 . This molecular profile was maintained on sub-passage (Figure 5; Additional file 5).

In two VRQ/VRQ animals the molecular mass of the unglycosylated band was higher than that observed in the other L-BSE samples (Figures 4C (lane 8) and 6). These samples also showed strong affinity with $\mathrm{P} 4$. In contrast to all other affected animals, one of these VRQ/VRQ sheep (48/13) had lymphoid tissue involvement showing a molecular profile with overall higher molecular mass for each band compared to the brain samples and was similar, but not identical, to the profile observed in the LRS of sheep affected with classical BSE (Figure 6; Additional file 6). However, strong detection with $\mathrm{mAb} \mathrm{P} 4$ was still evident in contrast to ovine classical BSE where $\mathrm{mAb}$ P4 detection was absent (lymphoid tissue) or markedly reduced (brain tissue). On this blot, the brain tissue from the L-BSE case had a molecular mass migration similar to the classical scrapie control when detected with Sha31.

\section{Discussion}

L-BSE can transmit experimentally, generally by the intracerebral route, to a wide range of hosts. These include cattle [36-39], sheep [40-42] and this report, lemurs [43], macaques [23, 24], hamsters [25, 44, 45] and transgenic mice overexpressing bovine, ovine or human $\operatorname{PrP}[20,25-27,39,42,44,46-48]$. In contrast to classical BSE, L-BSE does not transmit to wild type [20] Spiropoulos and Simmons, unpublished data] or transgenic mice that overexpress murine $\operatorname{PrP}[45,47]$, although exceptions have been reported [20].

There is evidence that, unlike classical BSE [49], L-BSE [20, 25, 42, 44, 45, 47], and H-BSE [21, 47, 50] do not always remain stable after intra- or inter-species experimental transmission. In some of these transmissions a phenotype shift from both L-BSE and H-BSE towards C-BSE has been reported [42, 47], on occasions only after sub-passage [25, 44, 45]. Such phenotype shifts have also been observed with other animal TSEs $[46,51]$.

The present study suggests that L-BSE remains stable on serial passage through sheep with a partial phenotype shift, associated with overt lymphoreticular involvement, observed only in one animal. The observation of a BSElike labelling pattern in the LRS of this sheep, together with the biosecurity measures that were in place, and the absence of similar observations in any of the other VRQ/ VRQ sheep, including the two genotype matched controls, would argue against the otherwise "scrapie-like" phenotype in this sheep being attributable to infection with extraneous classical scrapie.

The disease phenotype observed after intracerebral inoculation of sheep with L-BSE does not resemble any previously known TSE in this species, but is very consistent regardless of ovine host $\mathrm{PrP}$ genotype. The two animals selected for sub-passage were chosen because of differences in clinical presentation, most notably that one $(1591 / 10)$ was positive on the scratch test, while the other one (98/11) was not. This was not in itself sufficient for them to be considered as different phenotypes, and all other phenotypic parameters in these animals were the same, but they represented the only diversity seen at that time in the study. The predominant clinical cataplectic syndrome reported in the primary challenge animals was present in all of the animals challenged in the subpassage study, regardless of which donor was used. All other 


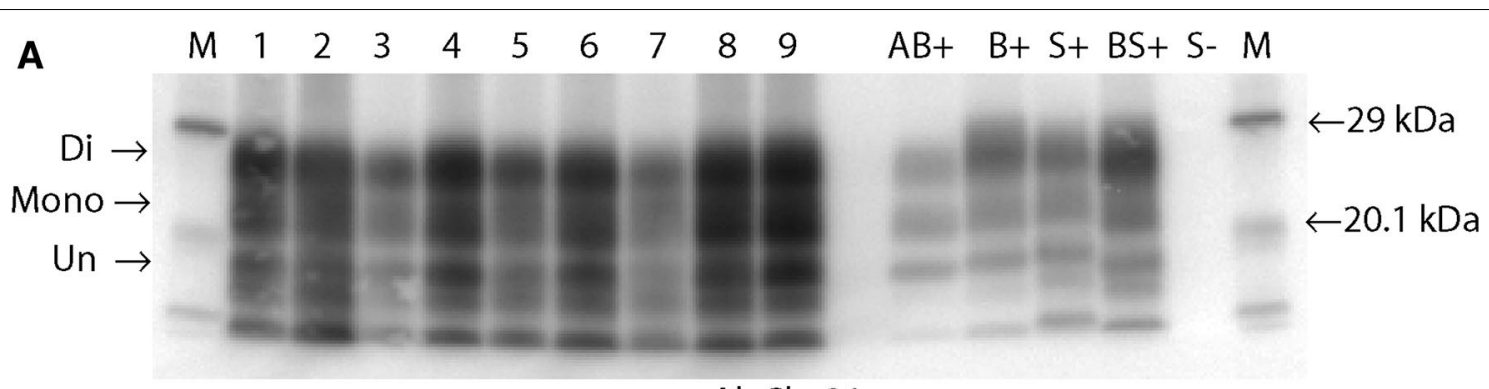

mAb Sha31
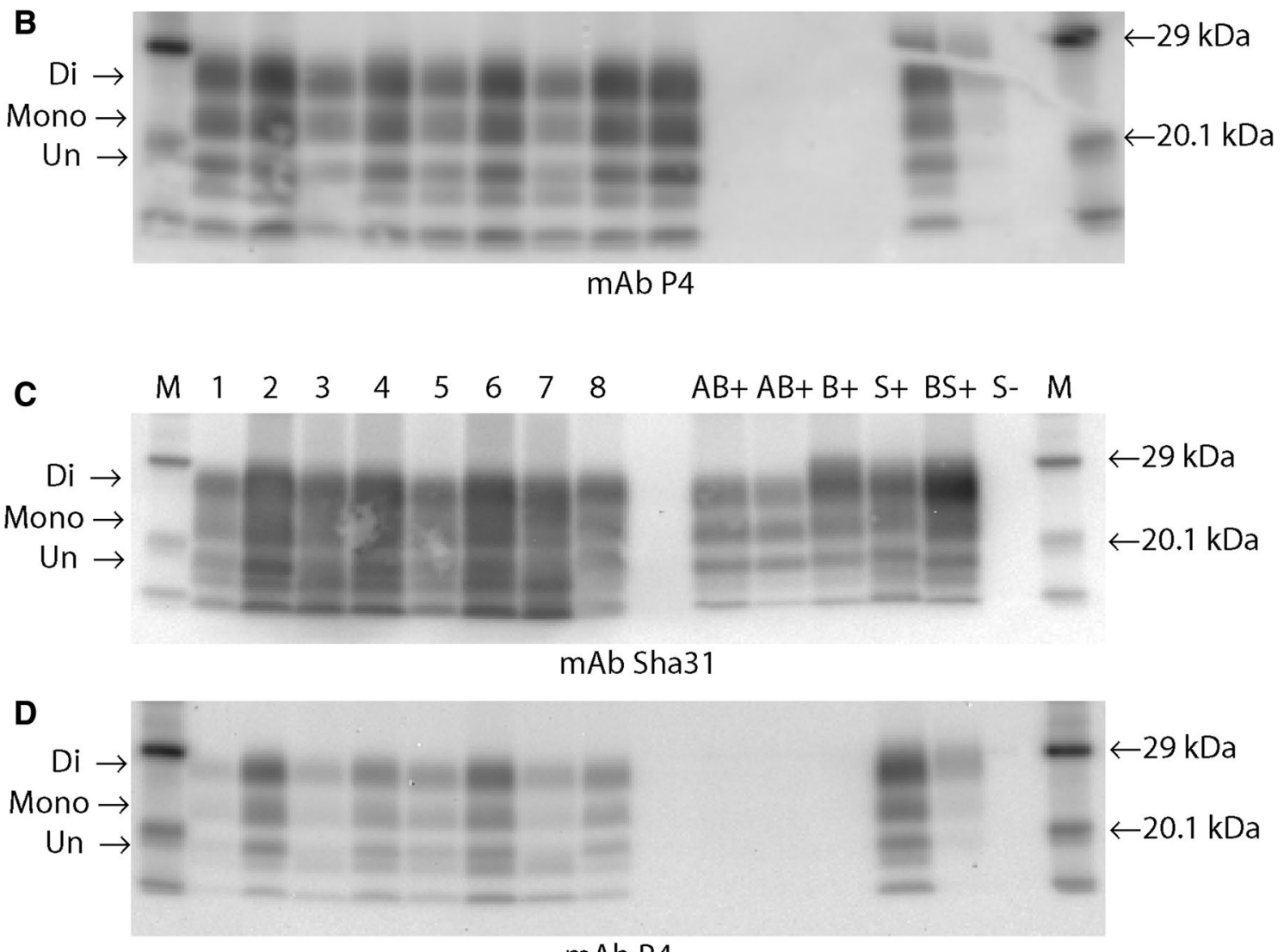

mAb P4

Figure 4 WB images from primary passage samples. A and $\mathbf{B}$ Nine representative recipients, homozygous for alanine (codon 136) detected by Sha31 (A), or P4 (B). (Lane 1, 63/11; lane 2, 3/11; lane 3, 457/11; lane 4 26/12; lane 5 112/12; lane 6, 182/12; lane 7, 3/13; lane 8, 98/11; lane 9, 455/11; $\mathrm{AB}+$, donor bovine L-BSE; B + , bovine C-BSE; S + , ovine Scrapie; BS + , experimental ovine CBSE; S-, negative sheep; M, molecular mass markers. A 1 min exposure, B 10 min exposure). C and D Eight representative recipients homozygous or heterozygous for valine (codon 136), detected by Sha31 (C) or P4 (D), (Lane 1, case 1591/10; lane 2, case 58/11; lane 3, 140/11; lane 4, 267/11; lane 5, 456/11; lane 6, 113/12; lane 7, 4/12; lane 8, 167/12; markers and controls as for A and B. C 1 min exposure, D 10 min exposure). There is low molecular mass migration of the unglycosylated band (arrow), similar to that of the donor bovine L-BSE (AB+), for all but one of the ovine recipients (VRQ/VRQ Lane 8 C, D) regardless of genotype. Similar di-;mono-glycosylated band ratios are also seen in all cases when detected by mAb Sha31 (see Additional file 4). All recipient samples, irrespective of genotype, are also detected with mAb P4 (B, D). In contrast the donor L-BSE case (AB+) is not. Following extraction with a Proteinase $K$ digestion step, may contain a mixture of varying molecular mass fragments, partly due to multiple cleavage sites and variability in resistance of $\mathrm{PrP}^{\mathrm{Sc}}$ to the concentration of the enzyme. The two additional lower bands observed in these profiles are regularly observed in diagnostic samples processed in this way. For diagnostic analysis they are disregarded. Only the standard three bands pertaining to the di, mono and un-glycosylated forms of PrPSc are considered relevant. 


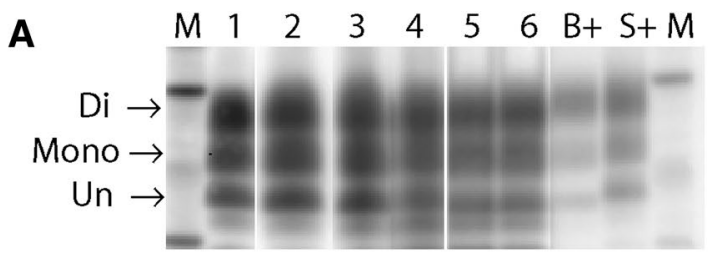

mAb Sha31

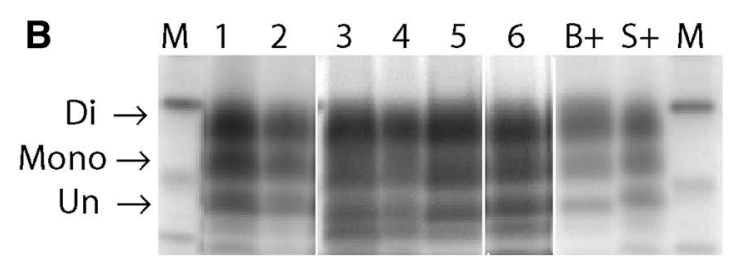

mAb Sha31

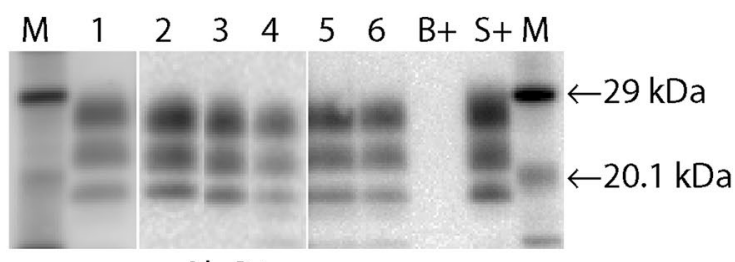

$\mathrm{mAbP} 4$

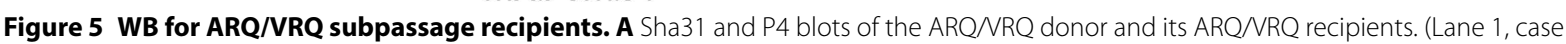

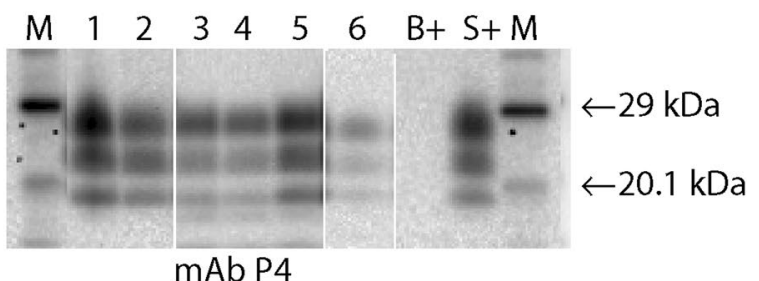
1591/10 (ARQ/VRQ Donor), Lane 2, case 6/14; Lane 3, case 73/14; Lane 4, case 76/14 Lane 5, case 78/14; Lane 6, case 79/14 M, Molecular marker; B+, Bovine BSE; S+, Classical Ovine Scrapie. This panel comprises a mixture of 1 and 10 min exposures). B Sha31 and P4 blots of the AFRQ/AFRQ donor and its ARQ/VRQ recipients (Lanes 1 and 2, case 98/11 (AFRQ/AFRQ Donor); Lane 3, case 80/14; Lane 4, case 81/14; Lane 5, case 82/14; Lane 6, case 75/14; M, molecular marker; S+, classical ovine scrapie; B+, bovine BSE. This panel comprises a mixture of 1 and 10 min exposures). In contrast the donor L-BSE case $(\mathrm{AB}+$ )molecular characteristics described for primary passage (Figure 4; Additional files $4 \mathrm{~A}-\mathrm{E}$ ) are retained on subpassage for all recipient animals regardless of the donor.

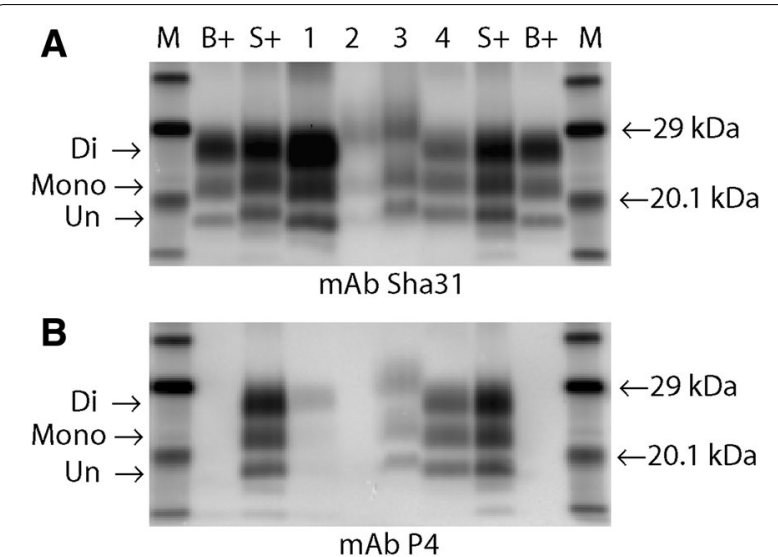

Figure 6 WB of brain and LRS from 48/13 (the VRQ/VRQ recipient with LRS involvement). A Detection with $\mathrm{mAb} S$ Sha31; B detection with mAb P4. (M, molecular markers; B+, bovine C-BSE control; S+, ovine classical scrapie control; Lane 1, ovine C-BSE brain; Lane 2, ovine C-BSE lymphoid tissue; Lane 3, ovine L-BSE lymphoid tissue (case 48/13); Lane 4, ovine L-BSE brain (case 48/13). 1 min exposure). The lymphoid tissue from the ovine C-BSE sample (lane 2) and L-BSE recipient (lane 3) show similar but not identical molecular profiles to each other with an overall higher mass migration pattern. However only the L-BSE sample is detected by mAb P4. The ovine C-BSE brain sample exhibits the expected profile characteristics of a low molecular mass migration, predominant diglycosylated band and mimimal detection with $\mathrm{mAb}$ P4. The ovine L-BSE brain sample (lane 4) exhibits a molecular mass migration that is higher than expected when compared to the primary and sub passaged results (Figures 4 and 5), appearing similar to the ovine scrapie control. However, the equal intensity of di and monoglycosylated bands can be observed. The sample was also detected by mAb P4. phenotypic characteristics were also the same, indicating the presence of a single strain, stable on subpassage.

The substantial reduction in survival time between the primary challenges and the subpassages is indicative of an initial transmission barrier between cattle and sheep. In the absence of any other phenotypic differences the differences in survival time between the different recipient genotype groups following subpassage is most likely an effect of host genotype.

There is no data available on whether this species adaptation might alter the host range or virulence of the isolate, as has been reported previously for classical BSE [52-55]. Previous reports on the transmission of L-BSE to sheep have only described the inoculation of animals that are ARQ/ARQ [40, 41] or ARQ/ARR [41]. This present study extends the range of sheep genotypes inoculated experimentally, to include the VRQ, and AFRQ haplotypes. In contrast to the unusual but consistent clinical signs reported here, no specific neurological signs have been described in the other studies.

Certain phenotypic parameters, such as survival times, vacuolation profiles and $\operatorname{PrP}^{\mathrm{Sc}}$ distribution patterns are not directly comparable between different species. However, Western blots are more specific to each TSE agent and are generally less affected by the host species.

In this study the WB profiles indicate that the molecular mass migration and glycoform ratio of the L-BSE donor isolate remained unchanged after passage in $A R Q / A R Q$ sheep, regardless of the codon 141 polymorphism, in agreement 
with those reported for other ARQ/ARQ L-BSE ovine challenges. In addition we have observed an increased reactivity with the N-terminal antibody which is not reported in other ovine L-BSE transmissions [40, 41]. This particular characteristic, normally associated with classical scrapie, is also observed on transmission of classical BSE to sheep but seen as a more gradual $\mathrm{N}$-terminal antibody detection that increases after serial subpassage [56]. It is possible that on the cross species transmission the atypical forms of BSE drive conversion of host $\operatorname{PrP}^{\mathrm{c}}$ to a form more closely resembling classical scrapie faster than classical BSE does.

Other host genotypes result in more variable Western blot characteristics, as demonstrated by the molecular mass migration shift towards a scrapie profile seen in two of the four VRQ/VRQ animals in this study and in one of the ARQ/ARR animals reported elsewhere [41].

Therefore it can be assumed that the species dependent phenotypic parameters, with the possible exception of survival time, which may be prolonged during interspecies transmission as a result of the transmission barrier, are specific for the L-BSE phenotype in sheep. However, concrete evidence that the strain identity has not changed during passage of the agent in sheep can be obtained by comparing bovine and ovine L-BSE sources after bioassay in mice. These bioassays are currently ongoing and will be reported separately.

There is an apparent susceptibility effect of host genotype which mirrors that seen for ovine C-BSE, with ARR/ ARR sheep appearing most resistant, and with longer incubation periods associated with $\mathrm{VRQ} / \mathrm{VRQ}$ animals [57-59]. This is not surprising as ovine PrP polymorphisms play an important role not only in classical scrapie, where their effect on susceptibility was first identified, but also in atypical or Nor98 scrapie. It is reasonable to assume that PrP polymorphisms in sheep would influence susceptibility, and in some cases phenotype, to almost any TSE exposure/challenge in these species.

The absence of detectable PrP in lymphoid tissues in $37 / 38$ positive animals, and the involvement of peripheral ganglia and muscle spindles concurs with the peripheral tissue distribution of L-BSE in cattle. This differs from the widespread lymphoreticular involvement seen in sheep challenged with C-BSE either orally [58] or following intracerebral inoculation ([60], Simmons, unpublished observations) and suggests that L-BSE affected animals are unlikely to readily disseminate the agent in the environment.

The identification of LRS involvement in one inoculated VRQ/VRQ animal, in which there was also stellate PrP deposition in the brain, might suggest the emergence of a new phenotype as a result of this interspecies transmission, or a stochastic event. To resolve this issue, mouse bioassays are ongoing to compare the biological phenotype of this isolate relative to the other inoculated animals. In this study, differences in WB characteristics were also observed between the CNS and LRS from this animal and the ovine C-BSE control. However, this observation is consistent with previous reports for classical scrapie in which it has been speculated that this reflects tissue-specific differences in glycosylation [61, 62].

Pruritus and weight loss are common features in sheep experimentally infected with classical BSE [35]. Although weight loss was also recorded frequently in sheep infected with L-BSE, clear evidence of pruritus was only seen in two ARQ/ARQ sheep whilst other sheep displayed the cataplectic form despite having the same prion protein genotype and being inoculated with the same inoculum. We have previously described similar divergent clinical syndromes in cattle $[38,63]$. Testing the response to scratching as an indicator of pruritus was less useful in this study because a response was also seen in control animals and a positive scratch test was only considered to be indicative of pruritus if it was progressive (e.g. mere pressure on the back elicited a response) and accompanied by wool loss.

The display of cataplexy, defined as sudden and transient episodes of loss of motor tone, (often subsequent to intense emotion in humans) in most of the sheep, sometimes accompanied by apparent narcolepsy, was unusual because it preceded other neurological signs suggestive of a TSE, e.g. ataxia or tremor. Although collapsing episodes have been reported in classical scrapie, these are usually seen infrequently and often at late-stage disease, when other signs associated with scrapie (e.g. pruritus, abnormal behaviour) are already present. There are only a few reports of collapsing episodes in scrapie-affected sheep, triggered by stress [64-66] but they are usually accompanied by pruritus, and not described as cataplexy-narcolepsy-like. There is a single report of cataplexy-narcolepsy in a lamb, which was associated with possibly impaired hypocretin function although the cause was not determined [67]. When initially presented with this sign in the first sheep, alternative diagnoses such as cardiac or neuromuscular disorders were considered but excluded based on the absence of abnormalities in heart rate, rhythm and electrocardiogram and the abrupt onset of and recovery from the collapse.

Given the unusual clinical presentation of these animals, any such cases occurring naturally would be unlikely to present as TSE suspects. From a surveillance perspective, we would therefore be reliant on the rapid screening tests applied to fallen stock and/or healthy slaughter populations to detect such cases should they arise. It is reassuring that ovine L-BSE presents with positive test results using all currently approved screening and confirmatory tests, indicating that such cases would be detected as positive within routine active surveillance activities. It is also reassuring 
that the existing confirmatory and discriminatory tests should identify these cases as unusual, and in some regards BSE-like in presentation, and they should result in referral for further investigation. However, caution should be exercised if Western immunoblot is the only confirmatory test applied since it has been observed here that a low molecular mass suggestive of L-BSE may not always be observed. As these cases are also strongly detected by the $\mathrm{N}$-terminal antibody they could present as very similar to scrapie in a field situation. For diagnostic purposes, when TSEs in small ruminants present a Western immunoblot profile that contains mixed characteristics of BSE and scrapie they are more readily visually identified as unusual when detection with an $\mathrm{N}$-terminal antibody is reduced or absent. Otherwise it can be more difficult to determine subtle differences in glycoform ratios and molecular mass migration, particularly when the overall signal strength is high.

No cases presenting with such phenotypic characteristics have been identified to date through the EU surveillance systems. However, given the growing trend to view and treat atypical BSE differently from classical BSE, it is important to know that L-BSE in sheep could be detected, should relaxation of the current preventative measures applied to the ruminant feed chain occur in the future.

\section{Additional files}

Additional file 1. Pruritic syndrome. Case 63/11 (ARQ/ARQ). This clip demonstrates progression in pruritic activity. Initially at $690 \mathrm{dpi}$ there are some head movements in response to scratching (inconclusive scratch test response). The scratch test is clearly positive at $865 \mathrm{dpi}$ when the sheep responded to scratching with lip licking and nibbling. There are no obvious gait abnormalities at this stage. Pruritic activity, such as rubbing and nibbling self, can be observed subsequently on CCTV from $840 \mathrm{dpi}$, which culminates in wool loss next to the tail head, indicated in the inset picture. Hind limb ataxia is now present at $949 \mathrm{dpi}$, which is most obvious when the sheep walks towards the other sheep, the wool loss subsequently remained but no skin lesions developed. Prior to cull at 956 $\mathrm{dpi}$, a positive scratch test can merely be elicited by applying pressure on the back.

Additional file 2. Cataplectic syndrome. Case $3 / 11$ (ARQ/ARQ). When all sheep are penned up for spray marking, this sheep is seen collapsing briefly when restrained at $924 \mathrm{dpi}$. A similar response is elicited when the handler attempts to catch the sheep and although the animal is getting up immediately, general ataxia and low head carriage with apparent loss of muscle strength in the neck ("floppy neck") is evident. CCTV images show lack of muscle tone when nudged by other sheep at the hay rack at 954 dpi. Scratching of the back result in lip and head movements (positive scratch test) although there is no evidence of wool loss. Following a collapse after the examination, the sheep is seen lying in the corner as if asleep and rises shortly after stimulated by hand clapping.

Additional file 3. Seizure-like syndrome. Case 1591/10 (VRQ/ARQ). The sheep displays a positive scratch test at $746 \mathrm{dpi}$, the last examination prior to cull. At $803 \mathrm{dpi}$ it is found dropping to the floor, and after walking slowly around the pen division it suddenly runs forward and drops to the floor, briefly vocalising, to end up in lateral position with all four limbs extended and trembling whilst the head is held between the front limbs. This episode only lasts a few seconds and the sheep gets up and runs away but drops down again at the edge of the pen division. Although the animal recovered from this episode it was culled on the same day.
Additional file 4. Antibody and glycoform ratios and molecular masses based on WB in Figure 4. A) Antibody detection ratios [Sha31 (Figure 4A): P4 (Figure 4B)] for L-BSE in animals that are homozygous for alanine at codon 136 (samples 1-9). It can be seen that the ratios in all of the challenged animals are very similar to that obtained from the classical scrapie control. Ratios calculated using the 1 min exposure for both antibodies. B) Antibody detection ratios [Sha31 (Figure 4C): P4 (Figure 4D)] for L-BSE in animals that are homozygous or heterozygous for valine at codon 136 (samples 1-8). The ratios in all of the challenged animals are generally higher than those in animals homozygous for alanine at codon 136 (A) but lower than that obtained from any of the bovine samples, with variable values sitting between the ovine classical scrapie and ovine BSE controls. This variability was not attributable to the codon 136 polymorphism, with samples 5, 6 and 8 being the homozygous animals. C) The glycoform profiles (relative quantity of the mono- versus di-glycosylated bands as observed in Figures $4 A$ and $4 C$, using $m A b$ Sha31). It can be seen that all of the sheep challenged with L-BSE have profiles which cluster with that of the bovine L-BSE donor, while bovine and ovine classical BSE are separate. D) Molecular masses for Sha31 based on Figure 4A. E) Molecular masses for Sha31 based on Figure 4C.

\section{Additional file 5. Antibody and glycoform ratios and molecular} masses based on WB in Figure 5. A) Antibody detection ratios (Sha31 and P4 (Figure 5A)). All ratios are calculated using the $1 \mathrm{~min}$ exposure for both antibodies. The codon 136 alanine/valine heterozygous ovine L-BSE donor (sample 1) and similarly heterozygous recipients (samples 2-6) are variable, but consistently lower than that for ovine classical BSE, and higher than the classical scrapie control. B) Antibody detection ratios [Sha31 and P4 (Figure 5B)]. All ratios are calculated using the 1 min exposure for both antibodies. The codon 136 alanine homozygous ovine L-BSE donor (sample 1) and alanine/valine heterozygous recipients (samples 2-6) are variable, but consistently lower than that for ovine classical BSE, and higher than the classical scrapie control. C) The glycoform profiles (relative quantity of the mono- versus di-glycosylated bands as observed in Figure 5A, using mAb Sha31). All the donor and recipient animals cluster with the classical scrapie control, and away from the ovine classical BSE. D) The glycoform profiles (relative quantity of the mono- versus di-glycosylated bands as observed in Figure 5B, using mAb Sha31). All the donor and recipient animals cluster with the classical scrapie control, and away from the ovine classical BSE. E) Molecular masses for Sha31 based on Figure 5A. F) Molecular masses for Sha31 based on Figure 5B.

Additional file 6. Antibody and glycoform ratios and molecular masses based on WB in Figure 6. A) Antibody detection ratios (Sha31 (Figure 6A): P4 (Figure 6B)) show that the ovine BSE control samples (samples 1 (brain) and 2 (lymphoid tissue)) match the classical BSE control, whereas the lymphoid tissue (sample 3) and brain (sample 4) from the L-BSE challenged animal show ratios closer to that of the classical scrapie control. All ratios are calculated using the 1 min exposure for both antibodies. B) The glycoform profiles (relative quantity of the mono- versus di-glycosylated bands as observed in Figure 6A, using mAb Sha31) demonstrate that the ovine L-BSE samples ( 3 and 4 ) are quite distinct from both the ovine classical BSE samples (1 and 2) and the classical scrapie controls. C) Molecular masses for Sha31 based on Figure 6A.

\section{Competing interests}

The authors declare that they have no competing interests.

\section{Authors' contributions}

Designed and managed the study: MMS, JS; executed the study, generated and analysed data: MMS, MJC,TK, CC, KEB, LT, SE, TF, DC, JS; drafted the manuscript: MMS, MJC,TK, CC, JS. All authors read and approved the final manuscript.

\section{Acknowledgements}

The authors are indebted to past and present staff of the Animal Sciences Unit and the Pathology Department, and in particular Jon Cooper, Laura Konold and Peter Bellerby for excellent technical support. This work was funded by Defra (projects SE1860 and SE1868). The New Zealand-derived scrapie-free 
recipient sheep were provided by Dr Hugh Simmons (Defra project SE1931). Statistical advice was provided by Dr Angel Ortiz-Pelaez.

\section{Author details}

${ }^{1}$ Department of Pathology, APHA Weybridge, Woodham Lane, Addlestone, Surrey KT15 3NB, UK. ${ }^{2}$ Animal Sciences Unit, APHA Weybridge, Woodham Lane, Addlestone, Surrey KT15 3NB, UK. ${ }^{3}$ Istituto Zooprofilattico Sperimentale del Piemonte, Liguria e Valle d'Aosta Sede Centrale di Torino, via Bologna, 148, 10154 Turin, Italy. ${ }^{4}$ Department of Virology, APHA Weybridge, Woodham Lane, Addlestone, Surrey KT15 3NB, UK.

Received: 17 May 2016 Accepted: 11 October 2016

Published online: 08 November 2016

\section{References}

1. Ironside JW (1998) Prion diseases in man. J Pathol 186:227-234

2. Bruce ME, Will RG, Ironside JW, McConnell I, Drummond D, Suttie A, McCardle L, Chree A, Hope J, Birkett C, Cousens S, Fraser H, Bostock CJ (1997) Transmissions to mice indicate that 'new variant' CJD is caused by the BSE agent. Nature 389:498-501

3. Hill AF, Desbruslais M, Joiner S, Sidle KCL, Gowland I, Collinge J, Doey LJ, Lantos P (1997) The same prion strain causes VCJD and BSE. Nature 389:448-450

4. Scott MR, Will R, Ironside J, Nguyen HO, Tremblay P, DeArmond SJ, Prusiner SB (1999) Compelling transgenetic evidence for transmission of bovine spongiform encephalopathy prions to humans. Proc Natl Acad Sci U SA 96:15137-15142

5. Wells GA, Scott AC, Johnson CT, Gunning RF, Hancock RD, Jeffrey M, Dawson M, Bradley R (1987) A novel progressive spongiform encephalopathy in cattle. Vet Rec 121:419-420

6. Ducrot C, Arnold M, de Koeijer A, Heim D, Calavas D (2008) Review on the epidemiology and dynamics of BSE epidemics. Vet Res 39:15

7. Bruce ME, Boyle A, Cousens S, McConnell I, Foster J, Goldmann W, Fraser H (2002) Strain characterization of natural sheep scrapie and comparison with BSE. J Gen Virol 83:695-704

8. Green R, Horrocks C, Wilkinson A, Hawkins SA, Ryder SJ (2005) Primary isolation of the bovine spongiform encephalopathy agent in mice: agent definition based on a review of 150 transmissions. J Comp Pathol 132:117-131

9. Stack MJ, Moore SJ, Davis A, Webb PR, Bradshaw JM, Lee YH, Chaplin M, Focosi-Snyman R, Thurston L, Spencer Yl, Hawkins SA, Arnold ME, Simmons MM, Wells GA (2011) Bovine spongiform encephalopathy: investigation of phenotypic variation among passive surveillance cases. J Comp Pathol 144:277-288

10. Foster JD, Hope J, Fraser H (1993) Transmission of bovine spongiform encephalopathy to sheep and goats. Vet Rec 133:339-341

11. Bellworthy SJ, Hawkins SA, Green RB, Blamire I, Dexter G, Dexter I, Lockey R, Jeffrey M, Ryder S, Berthelin-Baker C, Simmons MM (2005) Tissue distribution of bovine spongiform encephalopathy infectivity in Romney sheep up to the onset of clinical disease after oral challenge. Vet Rec 156:197-202

12. Eloit M, Adjou K, Coulpier M, Fontaine JJ, Hamel R, Lilin T, Messiaen S, Andreoletti $O$, Baron T, Bencsik A, Biacabe AG, Beringue V, Laude H, Le Dur A, Vilotte JL, Comoy E, Deslys JP, Grassi J, Simon S, Lantier F, Sarradin P (2005) BSE agent signatures in a goat. Vet Rec 156:523-524

13. Jeffrey M, Martin S, Gonzalez L, Foster J, Langeveld JP, Van Zijderveld FG, Grassi J, Hunter N (2006) Immunohistochemical features of PrP(d) accumulation in natural and experimental goat transmissible spongiform encephalopathies. J Comp Pathol 134:171-181

14. Spiropoulos J, Lockey R, Sallis RE, Terry LA, Thorne L, Holder TM, Beck KE, Simmons MM (2011) Isolation of prion with BSE properties from farmed goat. Emerg Infect Dis 17:2253-2261

15. Seuberlich T, Heim D, Zurbriggen A (2010) Atypical transmissible spongiform encephalopathies in ruminants: a challenge for disease surveillance and control. J Vet Diagn Invest 22:823-842

16. EFSA Biohaz Panel (EFSA Panel on Biological Hazards) (2014) Scientific Report: Protocol for further laboratory investigations into the distribution of infectivity of Atypical BSE. EFSA J 12:3978
17. Casalone C, Zanusso G, Acutis P, Ferrari S, Capucci L, Tagliavini F, Monaco S, Caramelli M (2004) Identification of a second bovine amyloidotic spongiform encephalopathy: molecular similarities with sporadic Creutzfeldt-Jakob disease. Proc Natl Acad Sci U S A 101:3065-3070

18. Biacabe AG, Laplanche JL, Ryder S, Baron T (2004) Distinct molecular phenotypes in bovine prion diseases. EMBO Rep 5:110-115

19. Jacobs JG, Langeveld JP, Biacabe AG, Acutis PL, Polak MP, Gavier-Widen D, Buschmann A, Caramelli M, Casalone C, Mazza M, Groschup M, Erkens JH, Davidse A, Van Zijderveld FG, Baron T (2007) Molecular discrimination of atypical bovine spongiform encephalopathy strains from a geographical region spanning a wide area in Europe. J Clin Microbiol 45:1821-1829

20. Capobianco R, Casalone C, Suardi S, Mangieri M, Miccolo C, Limido L, Catania M, Rossi G, Di Fede G, Giaccone G, Bruzzone MG, Minati L, Corona C, Acutis P, Gelmetti D, Lombardi G, Groschup MH, Buschmann A, Zanusso G, Monaco S, Caramelli M, Tagliavini F (2007) Conversion of the BASE prion strain into the BSE strain: The origin of BSE? PLoS Pathog 3:e31

21. Torres JM, Andreoletti O, Lacroux C, Prieto I, Lorenzo P, Larska M, Baron T, Espinosa JC (2011) Classical bovine spongiform encephalopathy by transmission of H-type prion in homologous prion protein context. Emerg Infect Dis 17:1636-1644

22. EFSA Biohaz Panel (EFSA Panel on Biological Hazards) (2015) Scientific Opinion on a request for a review of a scientific publication concerning the zoonotic potential of ovine scrapie prions. EFSA J 13:4197

23. Comoy EE, Casalone C, Lescoutra-Etchegaray N, Zanusso G, Freire S, Marce D, Auvre F, Ruchoux MM, Ferrari S, Monaco S, Sales N, Caramelli M, Leboulch P, Brown P, Lasmezas Cl, Deslys JP (2008) Atypical BSE (BASE) transmitted from asymptomatic aging cattle to a primate. PLoS One 3:e3017

24. Ono F, Tase N, Kurosawa A, Hiyaoka A, Ohyama A, Tezuka Y, Wada N, Sato Y, Tobiume M, Hagiwara K, Yamakawa Y, Terao K, Sata T (2011) Atypical L-type bovine spongiform encephalopathy (L-BSE) transmission to cynomolgus macaques, a non-human primate. Jpn J Infect Dis $64: 81-84$

25. Nicot S, Bencsik A, Morignat E, Mestre-Frances N, Perret-Liaudet A, Baron T (2012) Differentiation of prions from L-type BSE versus sporadic Creutzfeldt-Jakob disease. Emerg Infect Dis 18:2028-2031

26. Beringue V, Herzog L, Reine F, Le Dur A, Casalone C, Vilotte JL, Laude $H$ (2008) Transmission of atypical bovine prions to mice transgenic for human prion protein. Emerg Infect Dis 14:1898-1901

27. Kong Q, Zheng M, Casalone C, Qing L, Huang S, Chakraborty B, Wang P, Chen F, Cali I, Corona C, Martucci F, Iulini B, Acutis P, Wang L, Liang J, Wang M, Li X, Monaco S, Zanusso G, Zou WQ, Caramelli M, Gambetti P (2008) Evaluation of the human transmission risk of an atypical bovine spongiform encephalopathy prion strain. J Virol 82:3697-3701

28. Simmons HA, Simmons MM, Spencer Yl, Chaplin MJ, Povey G, Davis A, Ortiz-Pelaez A, Hunter N, Matthews D, Wrathall AE (2009) Atypical scrapie in sheep from a UK research flock which is free from classical scrapie. BMC Vet Res 5:8

29. Konold T, Phelan $L$ (2014) Clinical examination protocol for the detection of scrapie. Vet Rec 174:257

30. Wells GAH, Hawkins SA (2004) Animal models of transmissible spongiform encephalopathies: Experimental infection, observation and tissue collection. In: Lehmann S, Grassi J (eds) Techniques in prion research. Methods and tools in biosciences and medicine. Birkhäuser Verlag, Basel, pp 37-71

31. Ligios C, Jeffrey M, Ryder SJ, Bellworthy SJ, Simmons MM (2002) Distinction of scrapie phenotypes in sheep by lesion profiling. J Comp Pathol 127:45-57

32. Simmons MM, Konold T, Simmons HA, Spencer YI, Lockey R, Spiropoulos J, Everitt S, Clifford D (2007) Experimental transmission of atypical scrapie to sheep. BMC Vet Res 3:20

33. Gonzalez L, Martin S, Jeffrey M (2003) Distinct profiles of PrP(d) immunoreactivity in the brain of scrapie- and BSE-infected sheep: implications for differential cell targeting and PrP processing. J Gen Virol 84:1339-1350

34. Moore SJ, Simmons M, Chaplin M, Spiropoulos J (2008) Neuroanatomical distribution of abnormal prion protein in naturally occurring atypical scrapie cases in Great Britain. Acta Neuropathol 116:547-559

35. Konold T, Bone G, Vidal-Diez A, Tortosa R, Davis A, Dexter G, Hill P, Jeffrey M, Simmons MM, Chaplin MJ, Bellworthy SJ, Berthelin-Baker C (2008) 
Pruritus is a common feature in sheep infected with the BSE agent. BMC Vet Res 4:16

36. Balkema-Buschmann A, Ziegler U, McIntyre L, Keller M, Hoffmann C, Rogers R, Hills B, Groschup MH (2011) Experimental challenge of cattle with German atypical bovine spongiform encephalopathy (BSE) isolates. J Toxicol Environ Health A 74:103-109

37. Fukuda S, Iwamaru Y, Imamura M, Masujin K, Shimizu Y, Matsuura Y, Shu Y, Kurachi M, Kasai K, Murayama Y, Onoe S, Hagiwara K, Sata T, Mohri S, Yokoyama T, Okada H (2009) Intraspecies transmission of L-type-like bovine spongiform encephalopathy detected in Japan. Microbiol Immunol 53:704-707

38. Konold T, Bone GE, Clifford D, Chaplin MJ, Cawthraw S, Stack MJ, Simmons MM (2012) Experimental $\mathrm{H}$-type and L-type bovine spongiform encephalopathy in cattle: observation of two clinical syndromes and diagnostic challenges. BMC Vet Res 8:22

39. Lombardi G, Casalone C, D'Angelo A, Gelmetti D, Torcoli G, Barbieri I, Corona C, Fasoli E, Farinazzo A, Fiorini M, Gelati M, lulini B, Tagliavini F, Ferrari S, Caramelli M, Monaco S, Capucci L, Zanusso G (2008) Intraspecies transmission of BASE induces clinical dullness and amyotrophic changes. PLoS Pathog 4:e1000075

40. Matsuura Y, Iwamaru Y, Masujin K, Imamura M, Mohri S, Yokoyama T, Okada H (2013) Distribution of abnormal prion protein in a sheep affected with L-type bovine spongiform encephalopathy. J Comp Pathol 149:113-118

41. Nicot S, Bencsik A, Migliore S, Canal D, Leboidre M, Agrimi U, Nonno R, Baron T (2014) L-type bovine spongiform encephalopathy in genetically susceptible and resistant sheep: changes in prion strain or phenotypic plasticity of the disease-associated prion protein? J Infect Dis 209:950-959

42. Migliore S, D'Agostino C, Marcon S, Di Bari M, Vaccari G, Esposito E, Sezzi E, Chiappini B, Conte M, De Grossi L, Casalone C, Agrimi U, Nonno R (2011) Experimental BASE in sheep displays molecular PrPSc variations depending on the PrP genotype. Prion 5:67-68

43. Mestre-Frances N, Nicot S, Rouland S, Biacabe AG, Quadrio I, PerretLiaudet A, Baron T, Verdier JM (2012) Oral transmission of L-type bovine spongiform encephalopathy in primate model. Emerg Infect Dis 18:142-145

44. Nicot S, Baron T (2011) Strain-specific barriers against bovine prions in hamsters. J Virol 85:1906-1908

45. Shu Y, Masujin K, Okada H, Iwamaru Y, Imamura M, Matsuura Y, Mohri S, Yokoyama T (2011) Characterization of Syrian hamster adapted prions derived from L-type and C-type bovine spongiform encephalopathies. Prion 5:103-108

46. Espinosa JC, Herva ME, Andreoletti O, Padilla D, Lacroux C, Cassard H, Lantier I, Castilla J, Torres JM (2009) Transgenic mice expressing porcine prion protein resistant to classical scrapie but susceptible to sheep bovine spongiform encephalopathy and atypical scrapie. Emerg Infect Dis 15:1214-1221

47. Beringue V, Andreoletti O, Le Dur A, Essalmani R, Vilotte JL, Lacroux C, Reine F, Herzog L, Biacabe AG, Baron T, Caramelli M, Casalone C, Laude H (2007) A bovine prion acquires an epidemic bovine spongiform encephalopathy strain-like phenotype on interspecies transmission. J Neurosci 27:6965-6971

48. Baron T, Bencsik A, Biacabe AG, Morignat E, Bessen RA (2007) Phenotypic similarity of transmissible mink encephalopathy in cattle and L-type bovine spongiform encephalopathy in a mouse model. Emerg Infect Dis 13:1887-1894

49. Torres JM, Espinosa JC, Aguilar-Calvo P, Herva ME, Relano-Gines A, VillaDiaz A, Morales M, Parra B, Alamillo E, Brun A, Castilla J, Molina S, Hawkins $\mathrm{SA}$, Andreoletti O (2014) Elements modulating the prion species barrier and its passage consequences. PLoS One 9:e89722

50. Bencsik A, Leboidre M, Debeer S, Aufauvre C, Baron T (2013) Unique properties of the classical bovine spongiform encephalopathy strain and its emergence from $\mathrm{H}$-type bovine spongiform encephalopathy substantiated by VM transmission studies. J Neuropathol Exp Neurol 72:211-218

51. Simmons MM, Moore SJ, Lockey R, Chaplin MJ, Konold T, Vickery C, Spiropoulos J (2015) Phenotype shift from atypical scrapie to CH1641 following experimental transmission in sheep. PLoS One 10:e0117063
52. Espinosa JC, Andreoletti O, Castilla J, Herva ME, Morales M, Alamillo E, San Segundo FD, Lacroux C, Lugan S, Salguero FJ, Langeveld J, Torres JM (2007) Sheep-passaged bovine spongiform encephalopathy agent exhibits altered pathobiological properties in bovine-PrP transgenic mice. J Virol 81:835-843

53. Padilla D, Beringue V, Espinosa JC, Andreoletti O, Jaumain E, Reine F, Herzog L, Gutierrez-Adan A, Pintado B, Laude H, Torres JM (2011) Sheep and goat BSE propagate more efficiently than cattle BSE in human PrP transgenic mice. PLoS Pathog 7:e1001319

54. Plinston C, Hart P, Chong A, Hunter N, Foster J, Piccardo P, Manson JC, Barron RM (2011) Increased susceptibility of human-PrP transgenic mice to bovine spongiform encephalopathy infection following passage in sheep. J Virol 85:1174-1181

55. Vickery CM, Lockey R, Holder TM, Thorne L, Beck KE, Wilson C, Denyer M, Sheehan J, Marsh S, Webb PR, Dexter I, Norman A, Popescu E, Schneider A, Holden P, Griffiths PC, Plater JM, Dagleish MP, Martin S, Telling GC, Simmons MM, Spiropoulos J (2014) Assessing the susceptibility of transgenic mice overexpressing deer prion protein to bovine spongiform encephalopathy. J Virol 88:1830-1833

56. Stack M, Gonzalez L, Jeffrey M, Martin S, Macaldowie C, Chaplin M, Thorne J, Sayers R, Davis L, Bramwell J, Grimmer S, Bellworthy S (2009) Three serial passages of bovine spongiform encephalopathy in sheep do not significantly affect discriminatory test results. J Gen Virol 90:764-768

57. McGovern G, Martin S, Jeffrey M, Bellworthy SJ, Spiropoulos J, Green R, Lockey R, Vickery CM, Thurston L, Dexter G, Hawkins SA, Gonzalez L (2015) Influence of breed and genotype on the onset and distribution of infectivity and disease-associated prion protein in sheep following oral infection with the bovine spongiform encephalopathy agent. J Comp Pathol 152:28-40

58. Bellworthy SJ, Dexter G, Stack M, Chaplin M, Hawkins SA, Simmons MM, Jeffrey M, Martin S, Gonzalez L, Martin S, Hill P (2008) Oral transmission of BSE to VRQ/NRQ sheep in an experimental flock. Vet Rec 162:130-131

59. Saunders GC, Lantier I, Cawthraw S, Berthon P, Moore SJ, Arnold ME, Windl O, Simmons MM, Andreoletti O, Bellworthy S, Lantier F (2009) Protective effect of the T112 PrP variant in sheep challenged with bovine spongiform encephalopathy. J Gen Virol 90:2569-2574

60. Houston F, Goldmann W, Foster J, Gonzalez L, Jeffrey M, Hunter N (2015) Comparative susceptibility of sheep of different origins, breeds and PRNP Genotypes to challenge with bovine spongiform encephalopathy and scrapie. PLoS One 10:e0143251

61. Madec JY, Groschup MH, Calavas D, Junghans F, Baron T (2000) Proteaseresistant prion protein in brain and lymphoid organs of sheep within a naturally scrapie-infected flock. Microb Pathog 28:353-362

62. Everest SJ, Ramsay AM, Chaplin MJ, Everitt S, Stack MJ, Neale MH, Jeffrey M, Moore SJ, Bellworthy SJ, Terry LA (2011) Detection and localisation of $\mathrm{PrPS}^{\mathrm{Sc}}$ in the liver of sheep infected with scrapie and bovine spongiform encephalopathy. PLoS One 6:e19737

63. Konold T, Nonno R, Spiropoulos J, Chaplin MJ, Stack MJ, Hawkins SA, Cawthraw S, Wilesmith JW, Wells GA, Agrimi U, Di Bari MA, Andreoletti O, Espinosa JC, Aguilar-Calvo P, Torres JM (2015) Further characterisation of transmissible spongiform encephalopathy phenotypes after inoculation of cattle with two temporally separated sources of sheep scrapie from Great Britain. BMC Res Notes 8:312

64. Scott PR, Henshaw CJ (1995) Increasing the accuracy of the provisional antemortem diagnosis of scrapie. Agri-Practice 16:21-25

65. Spengler D (1992) Bericht über den Ausbruch der Traberkrankheit [An outbreak of scrapie]. Tierarztl Prax 20:579-583

66. Konold T, Moore SJ, Bellworthy SJ, Terry LA, Thorne L, Ramsay A, Salguero FJ, Simmons MM, Simmons HA (2013) Evidence of effective scrapie transmission via colostrum and milk in sheep. BMC Vet Res 9:99

67. White EC, de Lahunta A (2001) Narcolepsy in a ram lamb. Vet Rec 149:156-157 